\begin{tabular}{ccc}
\hline & International Journal of Engineering \& Technology, $7(3.30)(2018) 580-582$ \\
SPC & International Journal of Engineering \& Technology \\
\hline
\end{tabular}

\title{
Community Domain and Work-Family Enrichment: an Exploratory Study
}

\author{
Zaiton Hassan $^{1 *}$, Dayang Kartini Abang Ibrahim², Nur Fatihah Abdullah Bandar ${ }^{3}$, \\ Surena Sabil ${ }^{4}$, Nik Norsyamimi Md Nor ${ }^{5}$ \\ ${ }^{1}$ Universiti Malaysia Sarawak \\ ${ }^{2}$ Universiti Malaysia Sarawak \\ ${ }^{3}$ Universiti Malaysia Sarawak \\ ${ }_{5}^{4}$ Universiti Malaysia Sarawak \\ ${ }^{5}$ Universiti Malaysia Sarawak \\ *Corresponding author E-mail:hzaiton@unimas.my
}

\begin{abstract}
Recently, the positive side of work-family interface, work-family enrichment has been highlighted. However, most research came from Western cultural context and mostly focus on work and family domain only. Therefore, this study aims to investigate community domains demands and resources and its relationship to work-family enrichment in the Eastern cultural context, i.e. Malaysia. Selfadministered questionnaire were answered by 506 employees from six organizations. It was found that family-work enrichment (FWE) is higher than work-family enrichment (WFE). Resources from neighbors and relatives were positively related to WFE and FWE. Interestingly, friends' resources were negatively related to WFE and FWE. The findings strengthened the link between resources and enrichment. This study has shown that support outside the workplace, particularly from relatives and neighbours are important in enhancing work-family and family work enrichment. Thus, organizations in collectivist society should create community supportive culture to enhance the experience of work family enrichment among the employees.
\end{abstract}

Keywords: work-family enrichment, family-work enrichment, community, resources, demands

\section{Introduction}

Work-family interface (WFI) has been extensively examined from Western perspectives. Greenhaus et al., (5) reported ninety five percent of work-family enrichment studies were conducted in Western developed countries. This suggests that work-family interface particularly, the positive interaction of work and family issues in non-Western contexts have been ignored even though changes in economic development, employment patterns and the use of technology are intensifying in developing countries.

Even though work and family interaction concept was first proposed by Seiber in 1974, only of late researchers begun to examine this proposition e.g. $(3,6,12,19)$. Based on theories such as the expansionist theory (1), some argue having multiple roles as a worker, parent and community member enhances the knowledge skills, and resources that could be utilized to improve performance at work and vice versa.

This study which was conducted in Malaysia, a collectivist society, should further our understanding of work life balance issues in a non-Western culture. The current study aimed to identify the relationship between demands and resources in community domains which include relatives, friends and neighbours and workfamily and family work enrichment.

\section{Literature Review}

\subsection{Works-Family Enrichment}

Previous research demonstrates work-family enrichment is bidirectional, that is enrichment could be from work to family or from family to work and these are conceptually distinct with unique antecedents and outcomes $(2,4,23)$. For instance, (8) reported that WFE predicted job performance positively; but not FWE.

Carlson et al., (7) defined enrichment as positive experiences gained from resources in one role enhance the performance of another role. These positive experiences can be transferred to other domain directly, or indirectly; via two paths; instrumental or affective. Resources can be in many forms such as skills and perspectives, flexibility and may be psychological, physical, social, and material in nature.

This study is based on Conservation of Resources Theory (COR) (14). From COR perspectives, a high level of work demands, ties individual resources, thus less time and energy remain for family and community role, which might lead, in turn, less WFE. Instrumental and emotional support from family members, relatives, friends or neighbours would protect energy- related resources, thus lead to higher FWE. 


\subsection{Antecedents of Enrichment}

Accepting other researchers' call for more research on antecedents and consequences of enrichment e.g. $(9,18)$ this study examines antecedents of work-family enrichment. By understanding the antecedents, interventions can be designed by organizations to develop the experience of enrichment among their employees.

We investigated community demands and resources in relation to work-family enrichment, as most previous studies focus only on work and family domains (for instance, (2). Researchers are urged to examine other life domains besides family, such as community and leisure, to capture more comprehensively roles played by individuals $(3,21$.

As community plays a more significant role in collectivist societies (15), it was included in this study. Community resources as a sense of community, community services, neighbourhood attachment and support from friends and neighbours. While, community demands encompass community participation such as time spent in formal volunteering and informal helping; contact with friends and neighbours within informal social networks (19).

Additionally we built on Voydanoff's study by extending the definition of community to incorporate relatives. We argue that the inclusion of relatives in the scope is important as this study was situated in a predominantly collectivist society, Malaysia. It is common for a collectivist society to have a greater involvement of relatives in daily life due to the interdependent nature of relationships (15). Thus the study will further our understanding on how community demands and resources influences f work-family enrichment in a non Western cultural context.

\subsection{Community Resources, Demands and Enrichment}

Greenhaus et al., (5) outlined a theoretical model of enrichment antecedents and consequences. They identified five category of resources as antecedents, which are skills and perspectives, psychological and physical, flexibility, social capital and material resources; that may contribute to higher enrichment between work and family. Particularly relevant to this study, is the social capital which is defined as cultivating social relations that can be utilized to improve individual functioning at work or family. The interpersonal relationship with relatives, friends and neighbors may provide information, social support (either instrumental or affective) which may enhance enrichment either at work or family domain.

In Western context, community resources (sense of community and support from friends) explained $2.0 \%$ of the variance in WFE (19). Friends support was also positively related to FWE (22). Voydanoff (20) also found that community resources may reduce work-family conflict but somehow not enhance work-family facilitation. In sum, community resources are related but not critical in influencing enrichment in the Western context.

In addition, different norms may be emphasized across domains, which makes transition across domains difficult and this difficulty may limit enrichment (20). For instance, in Malaysia, while at work, public sector organizations provide $100 \%$ paid maternity leave for 90 days for up to 3 children, yet within the family and community domains, quality and affordable child care centres are lacking (11). This mixed message makes it quite difficult for parents, particularly women to combine work and family responsibilities, which is likely to result in less enrichment.

Kirchmeyer (10) found more time (not less) in volunteer work and community participation were associated with greater job satisfaction and organisational commitment. In particular participation in community activities increases an individual's values and provides ideas at work as well as assists in developing management skills (10). This suggests that what is viewed as community demands could also result in positive aspects such as enrichment.

\section{Methodology}

The study was conducted among employees (executives, non executive, male, female) in six public and private organizations in Sarawak. Respondents were asked to complete a voluntary self-administered questionnaire and returned the questionnaires in the sealed through the human resource manager. About 506 employees (50.6\% response rate) participated in the study.

Table 1: The Research Instruments

\begin{tabular}{|c|c|c|c|c|}
\hline $\begin{array}{l}\mathbf{N} \\
\mathbf{0}\end{array}$ & Instruments & $\begin{array}{l}\text { Number } \\
\text { of Items }\end{array}$ & Sources & $\alpha$ \\
\hline 1 & WFE and FWE & 18 & (7) & $\begin{array}{c}.94 \\
\text { (WFE), } \\
.95 \\
\text { (FWE) }\end{array}$ \\
\hline 2 & $\begin{array}{l}\text { Demands from Rela- } \\
\text { tives }\end{array}$ & 4 & (19) & .77 \\
\hline 3 & Demands from Friends & 4 & (19) & .77 \\
\hline 4 & $\begin{array}{l}\text { Demands from Neigh- } \\
\text { bors }\end{array}$ & 4 & (19) & .77 \\
\hline 5 & $\begin{array}{l}\text { Resources from Rela- } \\
\text { tives }\end{array}$ & 4 & (19) & .84 \\
\hline 6 & Resources from Friends & 20 & $\begin{array}{l}\text { Procidano \& } \\
\text { Heller (1983) }\end{array}$ & .82 \\
\hline 7 & $\begin{array}{l}\text { Resources from Neigh- } \\
\text { bors }\end{array}$ & 3 & (19) & .79 \\
\hline
\end{tabular}

\section{Result and Findings}

More than half of the respondents were male, non-executives, in the age group of 35 to 45 , married with children. About half respondents had a working spouse. In term of ethnic and religion, half $(45 \%)$ were Malay and 50\% were Muslim,.

Table 2 represented means, standard deviations and intercorrelations for the variables. It was found that FWE has higher mean than WFE, and are both are positively related. We found WFE and FWE were significant and positively related to resources from neighbors $(\mathrm{r}=.21, \mathrm{p}<.05$ for WFE) and relatives $(\mathrm{r}=.13, \mathrm{p}<.05)$ but significant and negatively related to resources from friends $(\mathrm{r}$ $=-.16, \mathrm{p}<.05$ ). Meaning, high support from neighbors and relatives lead to high WFE and FWE, while high support from friends lead to lower WFE and FWE.

Table 2: Means, standard deviations and intercorrelations ( $\mathrm{N}=506$ )

\begin{tabular}{|lllll|}
\hline & Mean & SD & WFE & FWE \\
WFE & 3.81 & .59 & & $.77^{* *}$ \\
FWE & 3.90 & .56 & & \\
Demands from Neighbours & 1.68 & .62 & -.03 & -.05 \\
Demands from Friends & 2.01 & .63 & -.02 & .02 \\
Demands from Relatives & 2.01 & .67 & -.03 & -.07 \\
Resources from Neighbours & 2.61 & .59 & $.21^{* *}$ & $.21^{* *}$ \\
Resources from Friends & 1.63 & .43 & $-.16^{* *}$ & $-.18^{* *}$ \\
Resources from Relatives & 2.15 & .68 & $.13^{* *}$ & $.11^{*}$ \\
\hline
\end{tabular}

Note. ${ }^{*}, \mathrm{p}<.05, * *, \mathrm{p}<.01$

\section{Discussion \& Limitation}

This study aimed to examine relationship between demands and resources in community domain and enrichment in a non-Western context. We hoped to provide the first evidence of work-family enrichment antecedents incorporating the community domain.

As in previous Western studies (12), FWE was higher than WFE, demonstrating the importance of family in a collectivist society. If self-concept of the individual is strongly anchored in the family than at work, positive spillover from family domain to work domain is more likely to happen and vice versa (7), thus explaining the higher experience of FWE among the respondents.

Although this result similar to Western findings, the classification of family in a collectivist society is more than husband, wife and children. In collectivist, family includes the extended family 
members such as parents, grandparents, siblings and relatives, and other individuals 'adopted' as family (15). Therefore, the opportunity to experience FWE is higher because of more interactions with 'family members'.

Consistent with previous research, resources are more related to enrichment, supporting the expansionist theory that multiple roles can be resulted in positive impact. In the Conservation of Resources (COR) view, employees strive to maintain the resources that contribute to positive moods, higher knowledge, skills and also higher self esteem and security, which lead to WFE and FWE.

This study provide evidence that community resources, particularly neighbors are playing some significant role in WFE and FWE. In other Malaysian studies, neighbors provide instrumental assistance such as childcare and household tasks as well as emotional support to working individuals (16-17). Good neighborhood provides feeling of security and peace; which can be a part of important resources as proposed by Conservation of Resources. For instance, WFE occurred when skills and knowledge learn at workplace can be shared with the neighbors through neighborhood activities. Good relationship with neighbors increase individual social networking; which directly or indirectly may help in better functioning at work and family life, thus lead to FWE and WFE.

Interestingly, friends' resources decrease WFE and FWE. In other words, more support from friends associated with less enrichment. Some possible explantion may be due to reciprocical needs in the relationship. Support is usually seen as positive, however too much suppport can be viewed as demand, whereby it is sometimes difficult to differentiate between 'caring' and 'busy body'. Friends in collectivist society to a certain extent are pre determined (15). Therefore, demands; from friends have to be tolerated. Moreover, keeping harmony; not confronting openly is an important norm in collectivist society. Dealing with friends' demands in a tactful manner, in a way teaching an individual to be a better negotiator, more patient and more tolerance to differences. This may lead to decreasing in WFE and FWE.

Current study has some limitations . Firstly, the cross-sectional design which does not allow us to make conclusions about causality between independent and dependent variables. Using longitudinal designs in future research would rectify this limitation.

Secondly, in the work-family interface, there are two perspective in community; which are social relationship and infrastructure perspective (13). In this study, we only investigated community from a social relationship perspective i.e. relationship with relatives, neighbours and friends . Future research could investigate community from infrastructure perspective which refers to the physical context of a community (13) that could deter or support an opportunity for enrichment.

\section{Implication \& Conclusion}

Our findings have potentially important implications for organizations. This study has shown that support outside the workplace, particularly from neighbors and neighborhood is important in enhancing enrichment. In line with this suggestion, organizations could get involve in neighborhood activities. Activities at the community level could strengthen the bond among neighbors, which lead to enrichment.

The results could also provide evidence to persuade management to offer family-friendly policies and to create a family/community supportive culture in the organizations. Training could be provided to supervisors and employees on how to support individuals in combining their work, family and community responsibilities. To conclude, our findings contribute to a better understanding of predictors of enrichment in a non-Western context, i.e. Malaysia. Similar to Western findings, resources are more related to enrichment. Support outside the workplace, particularly from relatives and neighbours are important in enhancing workfamily and family work enrichment. Thus, organizations in collectivist society should create community supportive culture to enhance the experience of work family enrichment among the employees.

\section{References}

[1] Barnett, R. C., \& Hyde, J. S. (2001). Women, Men, Work, and Family: An Expansionist Theory. American Psychologist, 56(10), 781-796.

[2] Brough, P., Hassan, Z., \& O’Driscoll, M. (2014). Work-life enrichment. In Psychosocial Factors at Work in the Asia Pacific (pp. 323-336). Springer, Dordrecht.

[3] Frone, M. R. (2003). Work-family balance. In J. C. Quick \& L. E. Tetrick (Eds.), Handbook of occupational health psychology. (pp. 143162). Washington: American Psychological Association.

[4] Gordon, J. R., Whelan-Berry, K. S., \& Hamilton, E. A. (2007). The relationship among work-family conflict and enhancement, organizational work-family culture, and work outcomes for older working women. Journal of Occupational Health Psychology, 12(4), 350-364.

[5] Greenhaus, J. H., \& Powell, G. N. (2006). When Work And Family Are Allies: A Theory Of Work-Family Enrichment. Academy of Management Review, 31(1), 72-92.

[6] Grzywacz, J. G., \& Butler, A. B. (2005). The Impact of Job Characteristics on Work-to-Family Facilitation : Testing a Theory and Distinguishing a Construct. Journal of Occupational Health Psychology, 10(2), $97-$ 109.

[7] Carlson, D. S., Kacmar, K. M., Wayne, J. H., \& Grzywacz, J. G. (2006). Measuring the positive side of the work-family interface: Development and validation of a work-family enrichment scale. Journal of Vocational Behavior, 68(1), 131-164.

[8] Carlson, D. S., Ferguson, M., Kacmar, K. M., Grzywacz, J. G., \& Whitten, D. (2011). Pay It Forward: The Positive Crossover Effects of Supervisor Work-Family Enrichment. Journal of Management, 37(3), 770789.

[9] Wayne, J. H., Grzywacz, J. G., Carlson, D. S., \& Kacmar, K. M. (2007). Work-family facilitation: A theoretical explanation and model of primary antecedents and consequences. Human resource management review, 17(1), 63-76.

[10] Kirchmeyer, C. (1992). Perceptions of Nonwork-to-Work Spillover: Challenging the Common View of Conflict-Ridden Domain Relationships. [Article]. Basic \& Applied Social Psychology, 13(2), 231.

[11] Hassan, Z., \& Dollard, M. (2007). Work-life balance: An Introduction Sarawak Development Journal, 8, 48-65.

[12] Hill, E. J. (2005). Work-Family Facilitation and Conflict, Working Fathers and Mothers, Work-Family Stressors and Support. Journal of Family Issues, 26(6), 793-819.

[13] Hill, J. E., Grzywacz, J. G., Allen, S., Blanchard, V. L., Matz-Costa, C., Shulkin, S., et al. (2008). Defining and conceptualizing workplace flexibility. Community, Work \& Family, 11, 149-163

[14] Hobfoll, S. E. (1989). Conservation of Resources: A New Attempt at Conceptualizing Stress. American Psychologist, 44(3), 513-524.

[15] Hofstede, G., \& Hofstede, G. J. (2005). Cultures and organizations: Software of the mind. New York: McGraw Hill.

[16] National Population and Family Development Board Malaysia. (2004). Malaysian population and family survey. National Population and Family Development Board Malaysia, Kuala Lumpur.

[17] Samad, S. (2006). Assessing the effects of work and family related factors on women well-being. Journal of American Academy of Business, 9 $52-57$.

[18] van Steenbergen, E. F., Ellemers, N., \& Mooijaart, A. (2007). How work and family can facilitate each other: Distinct types of work-family facilitation and outcomes for women and men. Journal of Occupational Health Psychology, 12(3), 279-300.

[19] Voydanoff, P. (2004). The Effects of Work Demands and Resources on Work-to-Family Conflict and Facilitation. Journal of Marriage \& Family, 66(2), 398-412.

[20] Voydanoff, P. (2005). Social Integration, Work-Family Conflict and Facilitation, and Job and Marital Quality. . Journal of Marriage \& Family, 67(3), 666-679.

[21] Voydanoff, P. (2001). Conceptualizing community in the context of work and family. Community, Work \& Family, 4(2), 133-156.

[22] Wadsworth, L. L., \& Owens, B. P. (2007). The Effects of Social Support on Work-Family Enhancement and Work-Family Conflict in the Public Sector. Public Administration Review, 67(1), 75-87.

[23] Wayne, J. H., Randel, A. E., \& Stevens, J. (2006). The role of identity and work-family support in work-family enrichment and its workrelated consequences. Journal of Vocational Behavior, 69(3), 445-461. 